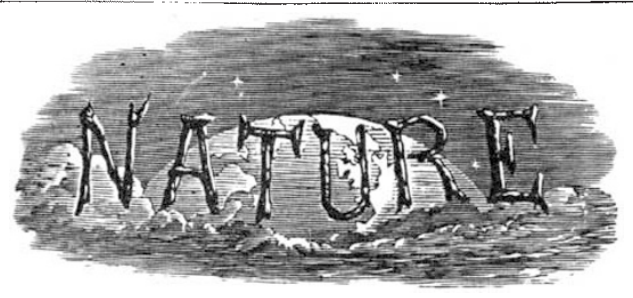

THURSDAY, DECEMBER I, I92I.

Editorial and Publishing Offices:

MACMILLAN \& CO., LTD.,

ST. MARTIN'S STREET, LONDON, W.C. 2.

Advertisements and business letters should be addressed to the Publishers.

Editorial communications to the Editor.

Telegraphic Address: PHUSIS, LONDON.

Telephone Number: GERRARD 8830.

\section{A Proposed National Institute of Industrial Micro-biology.}

$\mathrm{I}^{\mathrm{A}}$ no department of chemistry has greater progress been made during comparatively recent years than in biochemistry-the youngest and in some respects the most fascinating of the various branches into which chemical science has, for purposes of convenience, been partitioned. The beauty, the mystery, and the deep import of the phenomena with which biochemistry is concerned cannot fail to make a strong appeal to the scientific imagination, ever at a time when brilliant and fundamental discoveries in other branches of chemistry are so insistently claiming our attention and exciting our admiration and wonder.

Even if familiarity does not necessarily breed contempt, it often has a strong tendency to beget indifference, and this, coupled with the fact that biochemical phenomena are not, as a rule, of an arresting or spectacular nature, probably accounts largely for the lack of interest shown by chemists in general for so many years in this field of chemical inquiry. It is, however, this very absence of all that is spectacular or suggestive of difficulty or effort that makes the biochemical or life-processes so wonderful and so worthy of our closest study.

When we compare the synthetical methods of our laboratories with those of Nature we cannot fail to be struck with the essential crudity of the former. Great as were the intellectual achievements involved in the synthesis of, say, indigo, alizarin, nicotine, or camphor, it is certain that those and many other natural compounds are NO 27 I8, VOL. IO8] manufactured by the plant in a much more efficient and less wasteful manner.

By a close study of the way in which living organisms perform their remarkable feats of building up and breaking down, organic chemists will, no doubt, be enabled in course of time to dispense very largely with their fusion pots and their autoclaves and to work more closely on the lines of the living cell, at any rate so far as the synthesis of naturally occurring compounds is concerned. To this end intensive study of the phenomena of colloidal chemistry, and of the nature of enzyme action (including the function of "activators" and "accelerators") becomes of the highest moment. This aspect of the matter has recently received consideration in two important and very suggestive presidential addresses-that of Sir William Pope to the Society of Chemical Industry, in Montreal; and that of Dr. M. O. Forster to the chemistry section of the British Association, in Edinburgh. I may, perhaps, be permitted to point out that it also formed the leit motif of my recent Cantor lectures on "Micro-organisms and some of their Industrial Uses."

In the micro-organism as a living cell we have a chemical laboratory of the highest efficiency and of the most remarkable character, and could we but understand and imitate artificially the processes of synthesis and analysis which are so quietly and so regularly occurring in, say, a single cell of yeast, we should be not only within measurable distance of a new industrial organic chemistry, but also we should be a little nearer to an understanding of that greatest of all problems -the nature of life.

Whether, with the growth of chemical knowledge, the services of the living cell in connection with industrial operations will be ultimately dispensed with only the future can show, but certain it is that that time is still far distant. At present a number of important industries are more or less dependent on the activities of certain lowly organisms, and from the point of view of successful and efficient factory working alone, it is essential that we should possess a very thorough knowledge of the nature of those organisms and of the influence of environment on their chemical activities. From whatever point of view, therefore, we regard the study of industrial microbiology, it is clear that its encouragement and development are of high national concern. Anyone who makes an unbiased survey of the work done in this domain in various parts of the world 
cannot honestly feel satisfied with the contribution made by this country, especially when regard is had to our outstanding position as an industrial nation and to the immensity of our Empire and of our resources.

The disastrous indifference which we have for so long shown to the claims of scientific research appears now to be giving way to a feverish attempt to make up the leeway we have lost. It was in the hope that industrial micro-biology might participate in this new expenditure of energy that I was induced to make a special appeal for the foundation of a national institute in a paper read before the Society of Chemical Industry at the annual general meeting of the Society in July, 1919. At present the provision made for systematic instruction in industrial micro-biology, and for the study of the innumerable important problems on which it bears, is very inadequate, and there is not in this country nor, so far as I am aware, in the British Dominions, any institution devoted to a subject which is admittedly of such great technological importance. In connection with brewing and distilling, an immense amount of work has been, and is still being, done, but other industries in which micro-organisms play an important and even a predominant part have been left largely to take their chances, with-in some cases-the result that might easily have been predicted.

It is impossible, in the course of a short article such as this, to deal at any length with these various industries, or even to enumerate them all. I may, however, instance the manufacture of lactic and butyric acids, the wine, vinegar, and dairying industries, agriculture, baking, tanning, and the treatment of sewage, as among the more prominent. In addition to this the manufacture of enzyme preparations for many purposes is becoming daily of greater importance, and finally there is the question of the production of what may be termed synthetic food.

Assuming a national institute such as I have advocated to come into existence, it may be well to summarise very briefly the functions which it might usefully perform and the ground its activities might cover. The first and perhaps the most important object of a national institute would be to provide for the systematic prosecution of original research in connection with the above industries, and, in fact, with any industry in which micro-organisms or enzymes play an important part. That a great deal of very valuable work of this kind has been done and is now being done in this country is well known to all who are familiar with the subject, but the institutions in which this work is being carried out are scattered, and there can be no doubt that far better results could be obtained if the many closely related problems connected with the activity of organisms and of enzymes could be studied in a single institution adequately provided with all the necessary appliances and specimens, where the various workers in closely associated fields would have an opportunity of discussing their problems with one another.

In the next place the institute would serve as a centre for the specialised training of men intending to devote themselves to the teaching of micro-biology and biochemistry in our universities and technical schools, and also for the practical instruction of factory managers and other technical employés engaged in the various biological industries.

A further function which the proposed institute might fulfil would be that of providing breweries, distilleries, and other factories with any required organisms in pure culture and in sufficiently large quantities for industrial purposes. Facilities of this kind exist to some extent in France, and, I believe, to an even greater extent in Germany, but they are practically non-existent in this country.

Then again the institute would serve to house as complete a collection of industrial micro-organisms in pure culture as could be got together. Recently something in this direction has been done in the formation, by the Medical Research Council, of the national collection of type cultures at the Lister Institute, under the directorship of Dr. Ledingham, but although this and other similar collections will certainly be of considerable use, they cannot take the place of the much more exhaustive and complete collection which it would be one of the main functions of a national institute to accumulate.

I am aware that the labour involved in maintaining such a collection as I am indicating would be considerable, but it is of the routine kind, necessitating the employment merely of a few carefully trained laboratory attendants working under the supervision of the curator of the collection.

The institute would further serve as a central biochemical library. At the present time steps are being taken to form one large library devoted to chemical literature, and there is a very general feeling that all overlapping and unnecessary multiNO 27 I 8 , VOL. IO8] 
plication should be avoided. With this policy of concentration I am in the fullest agreement, but I think it will be generally admitted by all who know that the literature of the subject with which I am dealing is of a very highly specialised character; that it is, of course, more largely biological than chemical; and that many of the most important volumes and some even of the periodical journals are not, as a matter of fact, readily obtainable in any of our existing libraries. The general demand for certain works dealing with micro-biology is too small, and the books themselves are, perhaps, too costly and too highly specialised to appeal to the majority of the members of the library committees of our scientific societies.

Finally (and this would probably not be one of the least important of its functions) the proposed institute would serve as a central home for British micro-biological science and as the institute to which all workers in this field of natural knowledge, in every part of our Dominions, could apply for information, to which they could send rare specimens for identification or for investigation, and to which they could-subject to proper safeguards in the matter of priority-communicate any discovery of importance.

The subject, in its botanical aspects, is not one with which I can claim anything more than a very limited acquaintance, but I have some reason to believe that in our Colonies and overseas Dominions there are mycologists who would experience the advantage of such an institution, and who, while obtaining information themselves, might render great national service by contributing to our knowledge of the nature of many fungoid plant-diseases.

I am well aware of the admirable work in the domain of industrial micro-biology which is being done in a number of isolated institutions in this country, as well as in one or two well-known American colleges, in the Pasteur Institute in Paris, in the Institute for Fermentation Industries in Berlin, in the Carlsberg Laboratory in Copenhagen, and elsewhere. Each of these institutions, however, deals with this immense subject in certain of its aspects only, and, as compared with the scheme which I am advocating, they suffer from the great disadvantage that there is no coordination, and that, consequently, a combined attack on any of the big problems which are calling for solution is rendered very difficult, if not impossible. Among such problems I might instance the biochemical conversion of cellulose into fermentable sugar, from which industrial alcohol might be prepared on one hand, or synthetic foods on the other.

A few years before the outbreak of war the formation of a national institution somewhat on the lines I have suggested in this article was advocated by Paul Lindner, of the Institute for Fermentation Industries in Berlin. It need scarcely be said that the institute Lindner advocated would have had its home in Germany, and I feel strongly that it behoves us in this country to take steps to establish, on British soil, an institution which, although primarily intended to meet the needs of British workers, might ultimately receive the support of many of our American and Continental colleagues.

I know that one of the greatest difficulties, especially at the present time, in connection with the scheme will be that of obtaining sufficient money for the purpose. It seems to me, however, that a beginning might be made in a very modest manner. A large and expensive building would not, in the first instance, be necessary or even desirable, for in a matter of this kind much more would depend upon the selection of the right men than upon the size of the building or even upon the perfection of its equipment. Possibly some existing building, preferably in proximity to one of our university colleges, would be available. A very important point, however, is that it should be a separate national institute, and not a mere department of some existing teaching institution.

\section{A. Chaston Chapman.}

\section{Currents of Mathematical Thought.}

L'Idéal Scientifique des Mathématiciens: Dans l'Antiquité et dans les Temps Modernes. By Prof. Pierre Boutroux. (Nouvelle Collection scientifique.) Pp. 274. (Paris: Félix Alcan, I920.) 8 francs net.

THE aim of this work has been carefully 1 explained by the author, and the reader must continually bear that fact in mind. The book is not a history of mathematics; it is not an account of striking discoveries, or a criticism of mathematical methods, as such. It is an attempt, in the light of our present knowledge, to trace the principal currents of thought by which professional mathematicians during different periods have been consciously or unconsciously influenced. No hard-and-fast boundary lines have been laid down; it is merely for the sake of convenience NO 27 I8, VOL. IO8] 